\title{
Project based learning or problems becoming learned
}

\author{
N. M. Adams ${ }^{1} \quad$ J. Pienaar ${ }^{2} \quad$ C. J. Hayes ${ }^{3}$
}

(Received 9 January 2016; revised 15 April 2016)

\begin{abstract}
Project based learning is becoming widely accepted within engineering programmes across Australia. Supporters of this method of learning and teaching claim the method immerses the student in the subject and allows them to learn through hands on activities. Students are assessed based on their ability to complete a given project within a team environment. We examine the project based learning engineering programme at Central Queensland University and the students' opinions of its components. Present research and practice into authentic assessment and project based learning are investigated and comparison is made between these and the responses of the students.
\end{abstract}

http://journal . austms.org.au/ojs/index.php/ANZIAMJ/article/view/10452 gives this article, (C) Austral. Mathematical Soc. 2016. Published July 9, 2016, as part of the Proceedings of the 12th Biennial Engineering Mathematics and Applications Conference. ISSN 1446-8735. (Print two pages per sheet of paper.) Copies of this article must not be made otherwise available on the internet; instead link directly to this URL for this article. 


\section{Contents}

1 Introduction

C83

2 Context

C84

3 Methodology

C85

4 Participant demographics

C85

5 Results and discussion

C87

6 Conclusion

C96

References

C97

\section{Introduction}

It is important that engineering students gain an understanding of what engineers actually do and that academic programmes use industry-based assessment [13]. Professional bodies have found that engineering students obtain technical knowledge but have inadequate ability to apply it [10]. It is believed that project based learning (PBL) is a way to immerse students in the engineering environment, thereby providing a functional introduction to industry employment environments during the academic programme. Blumenfeld at al. describe PBL as "a comprehensive approach to classroom teaching and learning that is designed to engage students in investigation of authentic problems" [4].

Constructivist findings believe students gain a deeper understanding of material when they actively construct their understanding by working with and using ideas [18]. Within PBL, students reportedly engage in industry activities similar to, or based on, the activities of practising professionals. 
PBL is founded on the work of John Dewey [11] and has been used to teach medicine for many decades [1]. It is now used in many and varied disciplines from early childhood to post-graduate education [22, 17]. Some research demonstrated that students in PBL classrooms achieve higher scores than students in traditional classrooms [14, 19] while others, such as Alessio [1], found that the performance of students studying in PBL classes was no different to those taught by traditional means. Within the volumes of research conducted on PBL, no consensus on its value can be concluded and a heated debate on its effectiveness ensues [10, 20].

\section{Context}

The undergraduate engineering degree at Central Queensland University (CQU) requires students to have an Education Queensland mathematics B equivalent to enrol in the programme. "The Senior Syllabus in Mathematics B is a recommended precursor to tertiary studies in subjects with high demand in mathematics, especially in the areas of science, medicine, mining and engineering, information technology, mathematics, finance, and business and economics" [16]. Despite this, very limited mathematics knowledge is required to complete the first year PBL subjects. The CQU engineering degree is designed so that technical subjects, such as mathematics and physics, are studied simultaneously to the PBL unit(s), which are offered from first term in the first year and in two terms a year for the duration of the degree. The first year of the engineering degree is generic, with students studying one twelve credit point PBL subject, one six credit point mathematics subject and one six credit point physics subject in each of the two terms. After the first year students choose a major in either civil, mechanical, or electrical engineering and the PBL subjects become specialised. Students studying part-time or by distance education are advised to complete the PBL subjects prior to completing the mathematics and physics subjects. This is because the PBL subjects do not require any calculus or physics to complete. Regardless of 
specialisation, year or term, all PBL assessment is completed by portfolio.

It is believed that assessment drives learning; therefore, all assessment should be both authentic and aligned [21,3]. Authentic assessment measures student learning outcomes in real world scenarios and professional contexts while aligned assessment is the measurement of learning through tasks that are explicitly linked to the learning outcomes of the subject/programme [7]. In PBL, students complete projects without prior traditional lectures; the student is responsible for discovering facts and uncovering key concepts [1]. This assessment framework is the key to PBL and is recommended as best practice in engineering education [13].

\section{Methodology}

This study uses a mixed methods approach. Quantitative and qualitative data was obtained through an online quiz. The survey consisted of 24 questions (Figure 1) which were multiple choice or open responses. The questionnaire was designed using input from current and past engineering students. Quantitative data was evaluated using IBM SPSS Statistical Package version 22 and calculated at $\alpha=0.05$. Students enrolled in second year or above of a CQU engineering degree were invited to participate in the survey. The study sought to determine students' opinions of PBL at CQU.

\section{Participant demographics}

Two hundred and thirty students received the survey invitation, of which 46 completed it. Of those, 38 were male and 8 were female $(83 \%$ and $17 \%$, respectively). This distribution is similar to the actual male to female ratio of $87: 13$ in the engineering cohort [2]. Figure 2 shows the age distribution of both the survey participants and the engineering cohort. The sample has a 
Figure 1: Survey questions.

\section{Survey Questions}

1. What is your gender?

2. Which category below includes your age?

3. What level of education had you completed prior to commencing your engineering degree?

4. Which of the following best describes your student status?

5. Which of the following categories best describes your employment status?

6. Is your employment in the engineering field?

7. Did you do your first component of PBL concurrently with the technical subjects?

8. Do you feel you were adequately equipped with the mathematical and physics theory and understanding prior to conduction PBL?

9. Do you feel having completed mathematics and physics subjects prior to commencing the engineering project would have (did) yielded a better understanding of the problem and allowed you to solve it quicker and more easily?

10. Would you have preferred content from the PBL course to be taught as a traditional instructor led course?

11. Do you feel the learning outcomes related to the PBL scenario were achievable within the task?

12. Were you given adequate guidance on how to complete an objective peer assessment?
13. Did you feel the peer assessment provided and accurate and objective assessment of your performance?

14. How were teams selected?

15. Did you feel you got along with the team?

16. Did this affect the outcome of the project?

17. If any issues relating to the team/teamwork arouse, did the University handle them effectively?

18. Did you feel you were adequately prepared for dealing with the team dynamics?

19. Would the project have been more successful if you were taught 'soft' skills (giving/receiving feedback, leadership, followership and understanding team dynamics)?

20. Did you feel the team work associated with the PBL course adequately emulated that encountered in employment?

21. From what year do you think the PBL course should be run?

22. Please tell us the elements of PBL you liked.

23. Please tell us the elements of PBL you disliked.

24 . How would you describe your overall experience of PBL?

higher proportion of responses from younger students. The majority $(82 \%)$ of the respondents completed year 12 at high school, 20\% had TAFE (Technical and Further Education) qualifications, 16\% completed STEPS (a CQU bridging programme) and $4 \%$ previously studied at university. More than half (59\%) of the participants were studying full-time on-campus. The remainder were studying in distance mode. As distance students currently represent approximately $52 \%$ of the engineering cohort [6], the sample is slightly skewed toward the internal student. The employment rate of the participants was $78 \%$, with $46 \%$ employed in an engineering or cognate field. 
Figure 2: Age distribution of survey participants and engineering students. $70.0 \%$

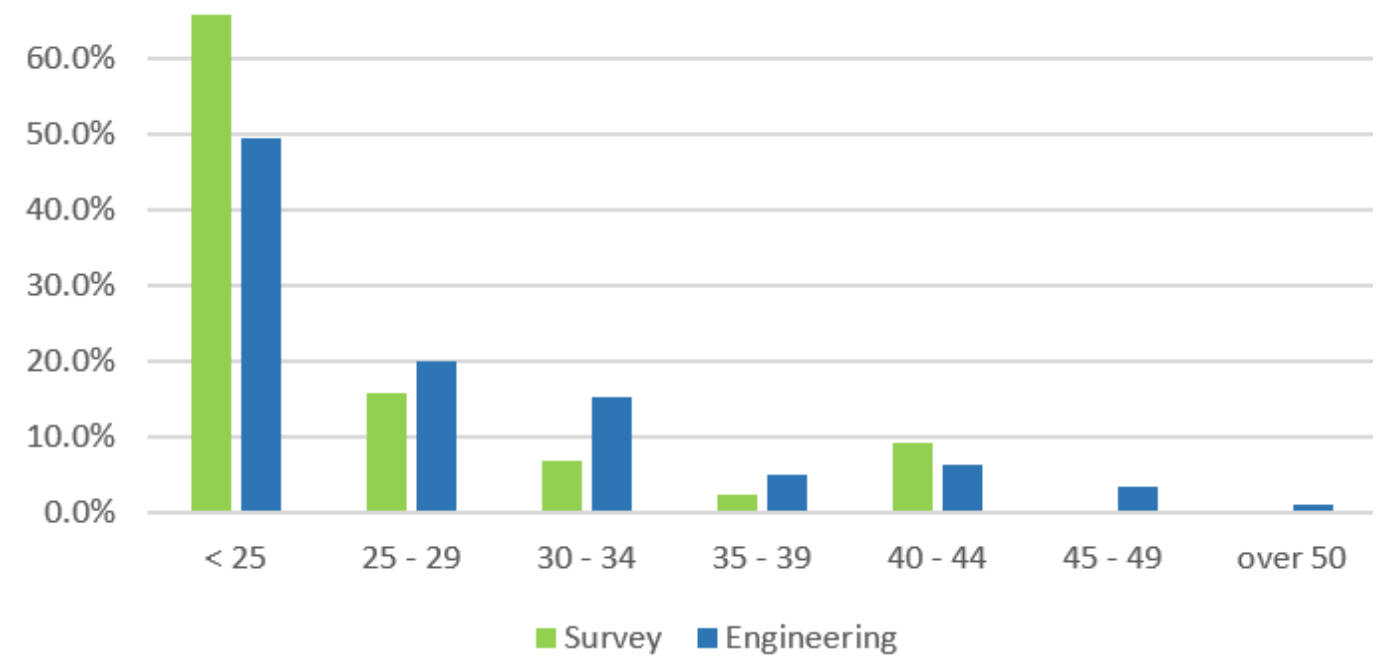

\section{Results and discussion}

Most $(77 \%)$ of the participants completed a standard first year and completed the PBL subjects with the technical subjects. Only $7 \%$ of the survey participants completed the technical subjects before the PBL subjects. One of the key learning objectives of PBL is for the student to "identify what they don't know and how they will learn it" [12]. Without the technical background, students may have unknown errors of omission which are difficult to identify [8]. Unknown errors of omission refers to not having the necessary knowledge, not recognising this knowledge is missing, and not knowing what to look for. As a result, students may not develop the easiest or best solution and, unless checked, will be unaware that a better solution exists; such knowledge may be necessary for future study [8].

The nature of PBL requires students to determine topics to be learnt and to develop the technical knowledge through investigation. This can result 
in knowledge gaps in mathematics and physics as these subjects have a hierarchical structure and must be learnt in a certain order [15]. Students were asked if they felt they had adequate mathematics and physics to complete the projects. The majority (65\%) felt that they did, $26 \%$ felt underprepared, and the remainder were uncertain. Based on mode of study, $54 \%$ of on-campus students and $82 \%$ of distance students felt they had adequate mathematics and physics to complete the projects. The reason many students felt they had the required mathematics is evident from their statements claiming that more advanced technical skills were not required for the PBL subjects, or that they were negated by the incorporation of teamwork (those in the team with the skills could complete that part of the project). Many of the comments from students indicated that even though they could pass the first level PBL subjects with the technical skills that they had, they recognise the benefits of a technical background. Some of the student comments included:

- The subject referred to requires little math or physics theory beyond primary school basics.

- No, the PBL subjects are very separate to technical subjects. But I think a more rigorous technical core base in the first year would be beneficial and also ensure the people who are enrolled know what they are in for.

- For most concepts contained within PBL, yes. But when we were attempting to model a solution using integrals in Engineering Skills 2, I had not completed the relevant maths subject and ended up feeling a bit lost.

- I remember expressing, during my first PBL subject, that I didn't feel as though I had the technical knowledge to solve the problem. The facilitator at the time told me this was part of engineering based problem solving and that acquiring the technical knowledge was often part of the solution.

Students were further asked if they thought completing mathematics and physics prior to commencing an engineering project would be beneficial; $68 \%$ responded positively, $52 \%$ on-campus and $94 \%$ distance. Students felt 
that there was a 'disconnect' between the technical subjects and the projects and they could be better integrated. Some students felt that more benefit could be gained from the projects if they had the technical skills first or at least were supplied with equations and examples of their use. Cross-tabulation and chi-squared tests $\left(\chi^{2}(1, N=41)=7.853, p=0.005\right)$ indicated the mode of study affects whether or not the student felt the mathematics and physics subjects should be taught before the PBL subjects. Some of the student comments included:

It would have allowed for more profound discoveries and I think an overall more exciting experience for Engineering Skills if I had the relevant Maths and Physics knowledge beforehand. For example: I can talk about a house in Nepal and talk about a wind load applied to it, but I can't calculate anything exciting about it (or at least begin to understand how to calculate something exciting). But once Engineering Physics A comes on the scene, all of a sudden I have a Bernoulli equation, and I can start to do some cool things to work out pressures acting on a surface based upon a wind load. It all makes a great deal more sense to do the more technical subjects first, because the PBL studies will really provide so much more advancement knowledge-wise and enjoyment for interested students.

Student opinions were divided on the benefits of having the PBL subjects taught as a traditional instructor led subject. Slightly more (54\%) participants, $56 \%$ on-campus and $50 \%$ distance, thought the structure of the subjects should remain the same. Some students felt that there was no other way the subjects could be taught, while others longed for a challenge and felt that the subjects were pitched low to cater to the less dedicated students. Further instruction was desired by students and some suggested maintaining PBL with embedded instruction and further guidance. There was a concern that without this, students could waste time on misdirected efforts. Students' comments included: 
- The content is not suited to another method.

- Too many non-dedicated students enrolled in the early stages of a university degree means that the PBL team projects become a frustration for many dedicated students (who will most likely pick up the slack) and generally the quality of learning (and the quality of the overall assignments) is greatly reduced so that assignments can merely be completed on time and cover the required content.

- I really enjoyed the PBL content but sometime wished there was more guidance from the lecturers as it can be overwhelming at times.

- Take away the amount of reflections and writing rubbish for a better knowledge of technical engineering concepts.

CQU provides all students with a subject profile that gives an overview of the subject and provides the learning outcomes. The learning outcomes are mapped to the assessment so that the student is aware of the subject learning outcomes covered by each assessment. As the PBL subjects are assessed by a single portfolio, all learning outcomes apply. Very few (7\%) students felt that the learning outcomes were not achievable within the project, a further $7 \%$ were unaware of the learning outcomes, and the remainder felt they were achievable. Students commented that the learning outcomes could be vague, there were too many, and much time was wasted in conveying, in writing, how they were achieved. Cross-tabulation and chi-squared tests $\left(\chi^{2}(10, N=41)=28.132, p=0.002\right)$ indicated that a student's former level of education may affect whether they felt the learning outcomes were achievable or not.

Teamwork is an important part of the engineering programme. It is a University graduate attribute and one of the Engineers Australia stage one competencies [9]. Teams may either be selected by the student or the University. The mode of study did not play a part in the selection process with $45 \%$ of the on-campus participants self-selecting their team and $44 \%$ of the distance participants doing likewise. Some students stay in the same team for their 
entire degree. The majority (87\%) of the participants felt they got along with the team. Students commented that there was usually one member of a team that brought the team down, and even though they continued relationships with some past team members, there were others that they did not want to work with. Ongoing relationships with past team members was seen as an important part of building a study support network. The relationships between team members were considered to affect the outcome of the project by $81 \%$ of the survey participants. Many students commented on good and bad team experiences and the effect these had on the project. Some students believed that, regardless of the team dynamics, the project should proceed and utilise each team member's skills and attributes, as would happen in an engineering employment situation. This thinking is in line with the findings of Borrego et al. [5] in that teams should utilise the unique skills of the members. Approximately $63 \%$ of the survey participants experienced issues relating to the team/teamwork; of these, $58 \%$ felt that the University handled them effectively. Some student comments related to team/teamwork included:

- Other students always have an effect on subject outcomes wherever there is contact between students.

- Absolutely yes. It made the assignments more about covering all the required topics of the report so the team could pass, as opposed to understanding what you could actually do with all the knowledge you developed while writing about those topics in the report.

- People never did any work I ended up always doing project myself. And will continue to do so people cannot be relied on.

- Getting along well made the work easier.

- The university handled issues in a manner which I would classify as 'diplomatic' from their standpoint.

As part of the assessment, students must provide peer assessments of each member of their team. These, together with academic observations, are used to substantiate individual student's claims made in the portfolio, and 
used to determine individual student grades. Approximately $66 \%$ of the participants felt they were given adequate guidance on how to complete an objective peer assessment. Cross-tabulation and chi-squared tests $\left(\chi^{2}(1, N=\right.$ $41)=90982, p=0.002$ ) indicated a difference between genders and their opinions of the adequacy of guidance given on completing peer assessment. There was a positive response from $76 \%$ of the males, while $86 \%$ of the females felt the guidance was not acceptable. When asked if they felt the peer assessment provided an accurate and objective assessment of their performance, $51 \%$ of students felt it did. Students commented that in many instances the feedback (peer assessment) was not released, so the opportunity to learn from constructive feedback was never explored or realised. Some individuals rated their colleagues highly to avoid conflict, while some teams conspired to all give good reports for their team members. It was felt that students that did not complete an adequate share of the workload should be unable to assess others. Participants also felt that personal opinions negated peer assessment. Student comments included:

- No, with the exception of those who were recognised for either performing exceptionally well or exceptionally badly, peer assessments are not considered as reputable feedback in my opinion.

- I knew of several students in my class from different teams who all checked off good marks for their colleagues because they just didn't want to deal with the trouble.

- These never work because nobody wants to bad mouth their peers or it'll happen to them, so everyone gives meaningless nice reviews.

- Disagreements within team over decisions meant personal opinions of people got in the way of the peer assessment.

Soft skills are important for team operation and dynamics. These skills may include: giving/receiving feedback, leadership, team membership and understanding team dynamics. For the most part, students felt prepared for dealing with team dynamics with $85 \%$ of participants responding positively 
to this question. Mature age students' comments indicated dealing with team dynamics may have been easier for them than for younger students, but these comments were not supported by the quantitative data. Some students felt that obtaining these skills was a gradual process, achieved over several or all of the PBL subjects in the programme. There was a comment that the preparation was obtained in high school and not through the University subjects. Student comments included:

- Being mature aged helps, the younger students struggled a bit.

- Skills like these are developed in years 1-12. If a student does not have them already, a week long course won't help them.

When asked if they thought soft skills should be taught, $60 \%$ of students said 'no'. Many of the respondents felt that students should have acquired these skills prior to commencing an engineering degree, either through work or school. The work ethics of some team members was questioned and a suggestion was made that every team should have a structure for development based on how individual personalities fit into roles and dynamics. Cross-tabulation and chi-squared tests $\left(\chi^{2}(4, N=38)=11.743, p=0.019\right)$ indicated a significant difference between age and the need to teach soft skills, with younger people being less inclined to feel the need for such skills to be taught. Former education also influenced students' opinions of the need to teach soft skills $\left(\chi^{2}(5, N=40)=13.472, p=0.019\right)$, with students having year twelve as their highest level of education believing that teaching soft skills would not have made the projects more successful. Students' comments included:

- These are skills that cannot really be 'taught' so to speak, and hence require experience in a group setting.

- The only way these teams could have been more successful, would be by changing people's work ethics.

Students were asked to speculate if the PBL subjects adequately emulated situations encountered in employment. The majority (56\%) felt that they did, $39 \%$ felt that they did not, and the remainder were unsure. Despite these 
results, many of the comments related to underperforming team members and the subsequent consequences in employment. From comments in this question and others, it is evident that the students are displeased when a team member is 'lazy' or does not contribute to the project but still passes the subject. Cross-tabulation and chi-squared tests $\left(\chi^{2}(2, N=38)=7.2\right.$, $p=0.027)$ indicated student employment affected their views of the validity of the teamwork associated with PBL. It was interesting that $68 \%$ of students not employed in engineering felt that the teamwork did not emulate that found in employment, while $74 \%$ of those working in engineering felt that it did. It appears that students not working in the engineering field have a distorted view of what the profession entails. Some typical student comments were:

- Yes, however a workplace is obviously going to bring on a more serious note in project development.

- If somebody in the workplace decided to rock up the first week as an online contractor and then didn't turn up at a team meeting after that: I would fire their asses.

- In the real world, as an employee, if you don't complete your work you lose your job or place in the company. Didn't seem to happen in the PBL subject, which is disappointing and showed me just how little someone else had to do to pass.

The majority of the respondents (59\%) felt that the PBL subjects should continue from first term, first year. A few (8\%) participants disliked PBL and thought it should never be included in the programme. The remainder of the students offered varying suggestions, although none suggested it as a capstone subject.

The question asking "what did you like about PBL?" was skipped by nineteen of the students. For the most part, the remaining students gave positive comments about the PBL subjects. Most of them enjoyed the projects and being able to work towards a target. Students' comments included: 
- Good to work on projects that emulate real-world.

- The undefined problems that students were required to devise a feasible solution for were sometimes an exciting opportunity to test ones critical thinking and problem solving abilities.

- I liked the communication between team members it encouraged.

When asked what they disliked, eighteen students skipped the question. The overwhelming concern regarded time. Even though time management is a skill that PBL is purported to develop [10], students found their efforts were frustrated and many of their tasks remained incomplete. The other overwhelming concern raised by the students related to teamwork. Other dislikes related to the use of a portfolio for assessment and related writing and reflections. Students also commented that they felt they were underprepared. A few students did not feel they gained anything. Some student comments included:

- The time restrictions that effected our ability to absorb the content thoroughly.

- Lazy students in the same team as me.

- I disliked the feeling of being overwhelmed and unprepared when you first read the project requirements. Maybe a small background lecture on the project and skills to help in a team environment would help.

The overall experience question was skipped by seventeen students. Those that did respond had varying experiences, from very good to very bad. A selection of student comments indicates the variance:

- Overall good, with bad team mates creating a bad experience.

- Highly positive and indicative of the engineering profession as a whole.

- Average. Easy and insightful to complete, but far too much writing required. 
- Frustrating coupled with the overwhelming feeling of lack of accomplishment.

- Having worked on projects as a civil cadet I felt it was a waste of my time and didn't teach me anything I wasn't doing at work.

- shit!!!!!

Although Litzinger, et al. [12] claimed PBL enables students to develop prerequisite knowledge and skill while developing new ones, the students felt they missed skills due to time constraints and the distribution of tasks that are an essential part of teamwork. Mills and Treagust [15] stated "a PBL approach may be insufficient for the acquisition of professional problem-solving skills in engineering due to the usual time scale of the problems and the range of activities that they include". Student comments indicated they desired more instruction. Blumenfeld at al. [4] suggested the "master-apprentice relationship" to learning-teaching. In this scenario, instruction is scaffolded, strategies for thinking and problem solving are taught, and responsibility is gradually released to the learner.

\section{Conclusion}

Project based learning is incorporated into many engineering programmes as it allows students to gain an understanding of what engineers actually do. It is based on constructivist findings that believe a deeper understanding of material is gained when students actively construct their understanding by working with and using ideas. As PBL requires students to learn by discovery or investigation and determine required topics, knowledge gaps may develop in technical subjects.

This article investigated students' opinions of certain elements of PBL including: technical knowledge; peer assessment; teamwork; and their general perception of PBL. The majority of students felt that the technical subjects 
were not required to complete the first level PBL subjects, due to the very limited mathematical knowledge required, although most indicated it would be beneficial. There was a near even split in students preferring PBL and traditional teaching methods. Students felt they were given adequate guidance for peer assessment and most felt the peer assessment was a reasonable assessment of their performance, although the student comments suggest peer assessment was subject to non-academic influences. Teamwork was one of the major concerns associated with PBL. Students felt that the consequences for underperforming team members should be greater. Most of the students agreed that the team work aspects of the projects emulated employment.

Most of the students enjoyed the PBL experience but many found certain team members detracted from this. Many of the student comments related to dissatisfaction with team members. Time was another overwhelming issue students had with PBL. They felt that much time was wasted on writing and reflecting. Student experiences ranged from very good to very bad.

This study has highlighted certain demographical relationships that should be considered when designing and implementing PBL subjects.

\section{References}

[1] H. Alessio. Student perceptions about and performance in problem-based learning. J. Scholar. Teach. Learn., 4(1):23-34, 2012. http://josotl.indiana.edu/article/view/1607. C84, C85

[2] Australian Bureau of Statistics. A comparison of the census and the labour force survey. Australian Labour Market Statistics, 6105.0, 2013. http: //www . abs.gov . au/AUSSTATS/abs@.nsf /Previousproducts / 6105. OFeature\%20Article3July\%202013? opendocument\&tabname= Summary\&prodno=6105. O\&issue $=\mathrm{July} \% 202013 \&$ num $=\& v i e w=. C 85$ 
[3] M. J. Bezuidenhout and H. Alt. 'Assessment drives learning': Do assessments promote high-level cognitive processing? S. Afr. J. High. Ed., 25(6):1062-1076, 2011. http://hdl.handle.net/10520/EJC37738. C85

[4] P. C. Blumenfeld, E. Soloway, R. W. Marx, J. S. Krajcik, M. Guzdial, and A. Palincsar. Motivating project-based learning: sustaining the doing, supporting the learning. Educ. Psychol., 26(3-4):369-398, 1991. doi:10.1080/00461520.1991.9653139. C83, C96

[5] M. Borrego, J. Karlin, L. D. McNair, and K. Beddoes. Team effectiveness theory from industrial and organizational psychology applied to engineering student project teams: A research review. J. Eng. Educ., 102(4):472-512, 2013. doi:10.1002/jee.20023. C91

[6] Central Queensland University, Australia. Student demographics. Central Queensland University Intranet, 2015. Viewed 8 August 2015. C86

[7] Central Queensland University, Australia. Glossary, 2016. https: //www.cqu.edu.au/about-us/structure/governance/glossary. C85

[8] D. Dunning, C. Heath, and J. M. Suls. Flawed self-assessment: Implications for health, education, and the workplace. Psych. Sci. Pub. Int., 5(3):69-106, 2004. doi:10.1111/j.1529-1006.2004.00018.x. C87

[9] Engineers Australia. Stage one competency standard for professional engineer, 2011. https://www.engineersaustralia.org.au/sites/ default/files/shado/Education/Program\%20Accreditation/ $110318 \% 20$ Stage $\% 201 \% 20$ Professional \%20Engineer.pdf. C90

[10] M. Jollands, L. Jolly, and T. Molyneaux. Project-based learning as a contributing factor to graduates work readiness. Eur. J. Eng. Educ., 37(2):143-154, 2012. doi:10.1080/03043797.2012.665848. C83, C84, C95 
[11] J. S. Krajcik and P. C. Blumenfeld. Project-based learning. In R. K. Sawyer, editor, The Cambridge Handbook of the Learning Sciences, pages 317-334. Cambridge University Press, 2006. doi:10.1017/cbo9780511816833.020. C84

[12] T. Litzinger, L. R. Lattuca, R. Hadgraft, and W. Newstetter. Engineering education and the development of expertise. J. Eng. Educ., 100(1):123-150, 2011. doi:10.1002/j.2168-9830.2011.tb00006.x. C87, C96

[13] S. Male and R. King. Best practice guidelines for effective industry engagement in Australian engineering degrees. Australian Council of Engineering Deans, Engineers Australia, 2014. http://arneia.edu.au/_asset/doc/_file/ Industry-Engagement-Guidelines-Final-27-June-2014.pdf. C83, C85

[14] R. W. Marx, P. C. Blumenfeld, J. S. Krajcik, B. Fishman, E. Soloway, R. Geier, and R. T. Tal. Inquiry-based science in the middle grades: Assessment of learning in urban systemic reform. J. Res. Sci. Teach., 41(10):1063-1080, 2004. doi:10.1002/tea.20039. C84

[15] J. E. Mills and D. F. Treagust. Engineering education: Is problem-based or project-based learning the answer? Austral. J. Eng. Educ., 3(2):2-16, 2003. http://pandora.nla.gov.au/pan/10589/20050128-0000/www . aaee.com.au/journal/2003/mills_treagust03.pdf. C88, C96

[16] Queensland Study Authority. Mathematics B Senior Syllabus, 2014. https://www.qcaa.qld.edu.au/senior/subjects/mathematics/ mathematics-b-2008. C84

[17] L. R. C. Ribeiro and M. d. G. N. Mizukami. Problem-based learning: A student evaluation of an implementation in postgraduate engineering education. Eur. J. Eng. Educ., 30(1):137-149, 2005. doi:10.1080/03043790512331313796. C84 
[18] V. Richardson. Constructivist Teacher Education: Building a World of New Understandings, chapter 1, Constructivist Teacher Education: Theory and practice, pages 3-14. Taylor and Francis, 1997. C83

[19] A. E. Rivet and J. S. Krajcik. Achieving standards in urban systemic reform: An example of a sixth grade project-based science curriculum. J. Res. Sci. Teach., 41(7):669-692, 2004. doi:10.1002/tea.20021. C84

[20] J. Strobel and A. van Barneveld. Pbl effectiveness, tensions, and practitioner implications. In A. Walker, H. Leary, C. E. Hmelo-Silver, and P. A. Ertmer, editors, Essential Readings in Problem-based Learning, pages 355-372. Purdue University Press, 2015. http://www. thepress . purdue.edu/titles/format/9781612493688. C84

[21] P. A. Tait. Assessment drives learning. J. Pharm. Prac. Res., 35(3):211-212, 2005. doi:10.1002/j.2055-2335.2005.tb00342.x. C85

[22] L. Torp and S. Sage. Problems as possibilities: Problem-based learning for K-12 education. 36(07):4042, 1998. doi:10.5860/choice.36-4042. C84

\section{Author addresses}

1. N. M. Adams, Learning and Teaching Services, Central Queensland University, Boundary Road, Mackay, Queensland 4740, Australia. mailto:n.adams@cqu.edu.au

2. J. Pienaar, Learning and Teaching Services, Central Queensland University, Kent Street, Sydney, N.S.W 2000, Australia.

3. C. J. Hayes, Academic Learning Services, Central Queensland University, Bruce Highway, Rockhampton, Queensland 4701, Australia. 